\title{
The future of climate-smart dryland cereals and legumes in South Asia and Sub-Saharan Africa
}

\author{
Sika Gbegbelegbe ${ }^{1}$, Swamikannu Nedumaran ${ }^{2}$, Aymen Frija ${ }^{3}$, Arega Alene ${ }^{1}$ \\ 1. International Institute of Tropical Agriculture (IITA) - Malawi \\ 2. International Crops Research Institute for the Semi-arid Tropics - India \\ 3. International Center for Agricultural Research in the Dry Areas - Tunisia
}

This document is part of a series of short papers on "The Future of X", produced as part of foresight-related research supported by the CGIAR Research Program on Policies, Institutions, and Markets, and edited by Keith Wiebe (IFPRI) and Steven Prager (Alliance of Bioversity and CIAT). These short papers are intended to provide a focused, forward-looking perspective on key issues to support discussion on food, land, and water systems transformation. We thank two anonymous reviewers for their comments on an earlier draft.

This is an accepted version presented as a pre-print. It is currently undergoing final revision, editing, and production. A final version will be made available at $h \mathrm{ttp}: / /$ foresight.cgiar.org.

\section{What is the issue?}

The drylands of sub-Saharan Africa (SSA) and South Asia (SA) cover 90 million hectares and they are characterized by high poverty levels, ranging from $49 \%$ in semi-arid South Asia to $83 \%$ in dry sub-humid Eastern Africa [1]. For many smallholders in these drylands, grain legumes and dryland cereals (GLDC) are a source of food, livelihood, and soil fertility.

Projections that involve a 'no climate change' scenario imply that the demand-supply gap for sorghum and millets in eastern and southern Africa will widen substantially in the future with the current level of technology development and policies [2]. The present demand for most GLDC crops in the dryland regions of SSA and SA is primarily met through local production $[2,3]$. However, climate change and variability, by altering patterns for rainfall, temperature, weather extremes and pests and diseases, could negatively affect the production of these crops and hence threaten food security and livelihoods in these drylands [4].

\section{What research has been done? What will the future climate bring?}

Climate modeling involving Global Circulation Models (GCMs) consistently predicts higher temperatures and mixed precipitation changes for the 2050 period in SSA and SA [5-7]. Sitespecific crop models that involve downscaled future climate data reveal that climate change could decrease sorghum yield by $36-12 \%$ in the Oxisol and Arenic paleustalts soil types in Samanko and Cinzana, Mali [8]. A few other studies have analyzed site-specific climate change 
impacts for pearl millet in India, Niger and Mali; groundnut in Mali; and chickpea in Ethiopia and Kenya [9-11]. These studies used downscaled climate change data and showed that climate change would have divergent effects on yields across sites. In addition, all these studies only considered the long-term change in temperature and rainfall brought by climate change.

In one study, GIS modeling was combined with yield equations to estimate the impact of longterm climate change on the yields of sorghum and millet in all soil types for countries located in eastern and southern Africa. The study results implied a yield reduction of more than $15 \%$ for pearl millet in the region due to long-term climate change [6].

The reduction in productivity for GLDC crops in the future would reduce the production of these crops, increase food prices and therefore lower food affordability, thus reducing calorie availability and leading to an increase in childhood malnutrition in the drylands of SSA and SA $[5,12]$.

\section{What research has been done? - What innovations are required to make GLDC crops climate-smart?}

Climate-smart GLDC crops should contribute to the three objectives of climate-smart agriculture, namely increased and stable crop productivity and income under climate change; enhanced adaptation and resilience to climate change; and reduced/mitigated greenhouse gas emissions [13]. Studies have mainly focused on the first objective of climate-smart agriculture. More specifically, foresight studies have identified some of the adaptation options required to enhance the productivity of GLDC crops under climate change in the drylands of South Asia and sub-Saharan Africa [14-16]. These options consist of improved varieties with resistance/tolerance to the abiotic stresses (drought and heat tolerance) induced by climate change and/or innovative agronomic and management practices (changing sowing date, irrigation, fertilizer, etc.) to enhance yields under climate change. For example, heat tolerance in sorghum has been identified as a trait that can enhance sorghum production under climate change for specific soils of west and central Sahel; in addition, sorghum intensification requiring mineral fertilizer could enhance yields in soils that would experience an increase in future rainfall in central Sahel [14]. Singh et al. (2014) also estimated the yield increase from heat and drought tolerance in chickpea for selected soils in India, Ethiopia, Kenya and Tanzania [10]. Few studies have gone beyond specific soils and agro-ecologies within countries to assess the effectiveness of climate smart GLDC crops across all soils within a country. For example, Islam et al. used gridded crop modeling to quantify the productivity impact of drought tolerance in sorghum and groundnut under climate change for all areas planted to sorghum and groundnut in India and selected countries in sub-Saharan Africa [17].

Structural changes across value chains were also identified among adaptation options that could increase yield and reduce current and future demand gaps. More specifically, Gbegbelegbe et al. found that closing the soybean demand gap under climate change in sub- 
Saharan Africa would require interventions to increase production and also enhance soybean processing capacity among producers in this region [18].

In terms of the other two objectives of climate-smart agriculture, one study has found that legume inclusion with maize (rotation/intercropping) when combined with minimum soil disturbance can increase farm income by $50 \%$ and $100 \%$ in the semi-arid areas of Malawi and Zambia, respectively [19]. Hence, such practices can enhance the resilience of smallholder communities. In addition, legume inclusion with maize when used alone or combined with other climate-smart practices can reduce greenhouse gas emissions [19].

\section{What are research gaps to make GLDC crops climate-smart?}

Even though studies have been conducted on the impact of long-term climate change on the production of GLDC crops in the drylands of South Asia and sub-Saharan Africa, some gaps remain. For example, in west Africa, the impact of climate change on cowpea production has only been studied for Benin Republic when Nigeria is the number one cowpea producer in the world. In South Asia, not much has been done. Such an oversight in the literature for South Asia and sub-Saharan Africa can be partly attributed to the fact that GLDC crops are considered drought-tolerant compared to dominant cereals like rice, maize and wheat; this is the case for sorghum, millet and cowpea. However, as shown by a few site-specific studies, the abiotic [8$11]$ and biotic $[20,21]$ stresses induced by climate change could negatively affect the production of GLDC crops and jeopardize food and nutrition security in the regions where they matter most. Future research should involve integrated impact assessment approaches which include gridded models to quantify the impact of long-term climate change on the production of GLDC crops in the drylands of SSA and SA.

The few studies that have analyzed adaptation options for GLDC crops primarily involve soilspecific analyses within a country. Future research should involve gridded crop modeling to identify the traits required to increase the productivity of GLDC crops under climate change for the drylands. Some crops which have not yet been studied in terms of climate change adaptation include cowpea, pigeon pea and faba bean (Figure 1). Both cowpea and pigeon pea are drought-tolerant, but they are also highly vulnerable to pests and diseases. Climate change will affect the incidence of the current pests and diseases for cowpea and pigeon pea [21]; it will also influence emerging biotic stresses for GLDC crops in general. Hence, future research should identify appropriate pest, disease, and weed management options required to enhance the productivity of GLDC crops under climate change. 

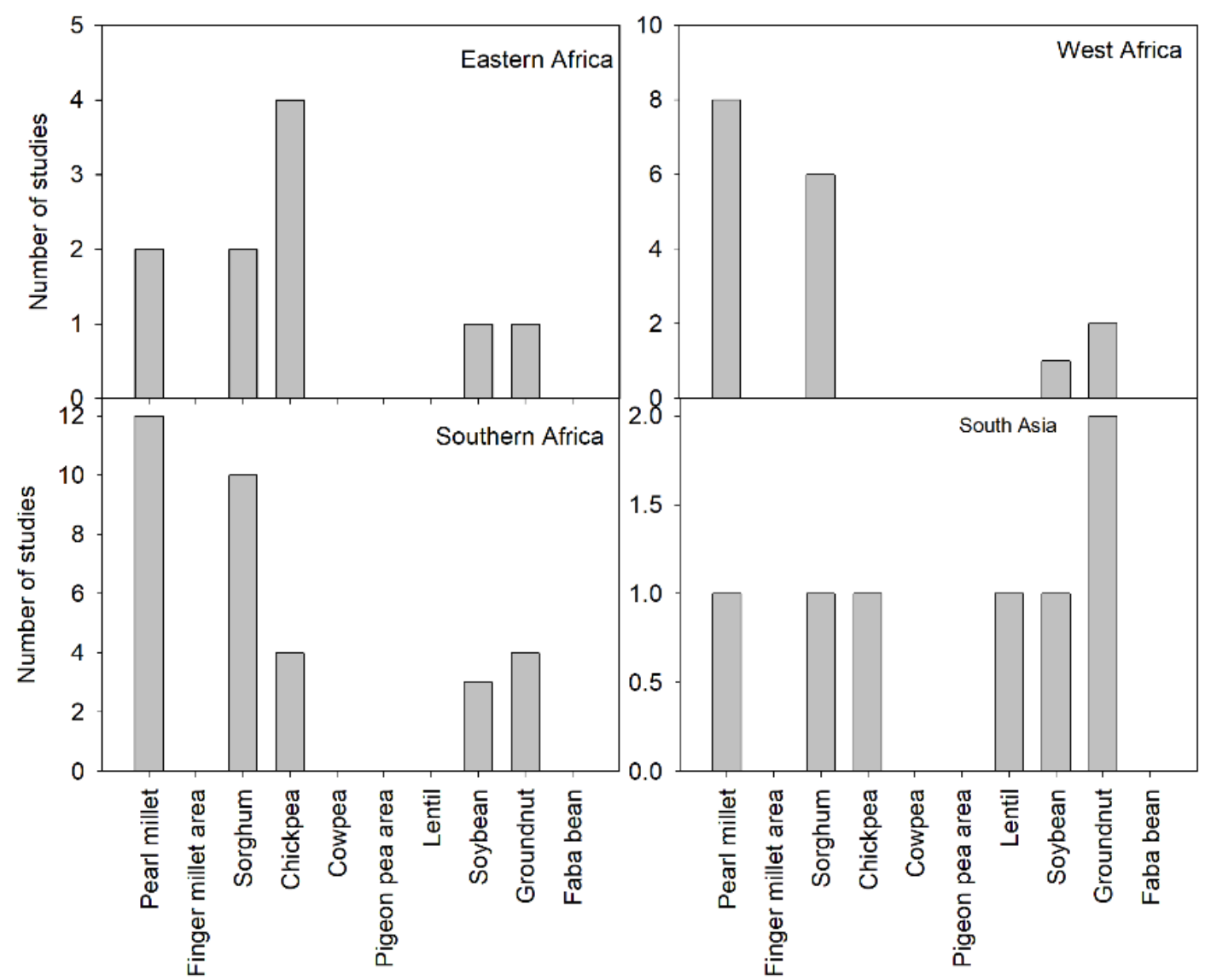

Figure 1: Number of climate change adaptation studies with projected future production for sub-Saharan Africa and South Asia under climate change

Most climate change adaptation studies focused on pearl millet and sorghum in southern Africa; South Asia and eastern Africa were the least studied regions (Figure 1). In addition, all studies focused on adaptation to the abiotic stresses from long-term climate change. Weather extremes were not considered and yet, the latter are changing globally in terms of frequency, intensity and duration. Hence, another future research avenue consists of identifying adaptation options to the abiotic stresses brought by long-term climate change and weather extremes for GLDC crops.

In conclusion, there's little scientific evidence that assesses the climate-smartness of GLDC crops. A few studies have identified some options to enhance the productivity of selected GLDC crops under climate change in specific environments. However, more needs to be done to cover a larger set of crops and environments through spatial modeling and to also consider weather extremes and climate-induced weeds, pests, and diseases. In addition, future research should use the concept of vulnerability to measure the impact of improved GLDC crops on adaptation and resilience for smallholder farmers in current and future years. Similarly, additional research should be conducted to assess the extent to which GLDC crops can reduce/mitigate greenhouse gas emissions today and in the future. Once there's enough evidence on the climate-smartness 
of improved GLDC technologies, they will be more effectively used under an uncertain climate in the drylands where they matter most.

\section{References}

1. Gumma, M. K. Characterization of GLDC Mega-environments. https://repo.mel.cgiar.org/handle/20.500.11766/10235 (2017).

2. Orr, A., Mwema, C., Gierend, A. \& Nedumaran, S. Sorghum and millets in Eastern and Southern Africa: facts, trends and outlook. (2016).

3. Nedumaran, S. Foresight Analysis for Grain Legumes and Dryland Cereals (GLDC). https://repo.mel.cgiar.org/handle/20.500.11766/10234 (2019).

4. Seneviratne, S. I. et al. Changes in climate extremes and their impacts on the natural physical environment. in Managing the Risks of Extreme Events and Disasters to Advance Climate Change Adaptation (eds. Field, C.B., V. Barros, T.F. Stocker, D. Qin, D.J. Dokken, K.L. Ebi, M.D. Mastrandrea, K.J. Mach, G.-K. Plattner, S. K. A. \& M. Tignor, and P. M. M.) 109-230 (Cambridge University Press, 2012).

5. Ringler, C., Zhu, T., Cai, X., Koo, J. \& Wang, D. Climate Change Impacts on Food Security in Sub-Saharan Africa. (2010).

6. Adhikari, U., Nejadhashemi, A. P. \& Woznicki, S. A. Climate change and eastern Africa: a review of impact on major crops. Food Energy Secur. 4, 110-132 (2015).

7. Almazroui, M., Saeed, S., Saeed, F., Islam, M. N. \& Ismail, M. Projections of precipitation and temperature over the South Asian countries in CMIP6. Earth Syst. Environ. 4, 297320 (2020).

8. Singh, P. et al. Quantifying potential benefits of drought and heat tolerance in rainy season sorghum for adapting to climate change. Agric. For. Meteorol. 185, 37-48 (2014).

9. Singh, P. et al. An assessment of yield gains under climate change due to genetic modification of pearl millet. Sci. Total Environ. 601, 1226-1237 (2017).

10. Singh, P. et al. Climate change impacts and potential benefits of drought and heat tolerance in chickpea in South Asia and East Africa. Eur. J. Agron. 52, 123-137 (2014).

11. Singh, P. et al. Potential benefits of drought and heat tolerance in groundnut for adaptation to climate change in India and West Africa. Mitig. Adapt. Strateg. Glob. Chang. 19, 509-529 (2014).

12. Mbow, C. et al. Food security. in (eds. Shukla, P. R. et al.) 113 (IPCC, 2020).

13. FAO. Climate-smart agriculture case studies 2021 - Projects from around the world. https://doi.org/10.4060/cb5359en (2021).

14. Guan, K., Sultan, B., Biasutti, M., Baron, C. \& Lobell, D. B. Assessing climate adaptation options and uncertainties for cereal systems in West Africa. Agric. For. Meteorol. 232, 291-305 (2017).

15. Kadiyala, M. D. M. et al. Modeling the potential impacts of climate change and adaptation strategies on groundnut production in India. Sci. Total Environ. 776, 145996 (2021).

16. Frija, A., Ourghemmi, H., Ismail, F., Gbegbelegbe, S. \& Swamikannu, N. Modeling the potential impacts of climate change and adaptation strategies on groundnut production 
in India. Methodx (forthcoming).

17. Islam, S. et al. Structural approaches to modeling the impact of climate change and adaptation technologies on crop yields and food security. Glob. Food Sec. 10, 63-70 (2016).

18. Gbegbelegbe, S. et al. Ex-ante evaluation of promising soybean innovations for subSaharan Africa. Food Energy Secur. 8, e00172 (2019).

19. Branca, G. et al. Assessing the economic and mitigation benefits of climate-smart agriculture and its implications for political economy: A case study in Southern Africa. J. Clean. Prod. 285, 125161 (2021).

20. Rao, M. S. et al. Pest scenario of Spodoptera litura (Fab.) on groundnut under representative concentration pathways (RCPs) based climate change scenarios. J. Therm. Biol. 94, 102749 (2020).

21. Mathukumalli, S. R. et al. Prediction of Helicoverpa armigera Hubner on pigeonpea during future climate change periods using MarkSim multimodel data. Agric. For. Meteorol. 228, 130-138 (2016). 